\title{
Adverse genomic alterations and stemness features are induced by field cancerization in the microenvironment of hepatocellular carcinomas
}

\author{
Darko Castven ${ }^{1, *}$, Michael Fischer ${ }^{1, *}$, Diana Becker ${ }^{1}$, Stefan Heinrich ${ }^{2}$, Jesper B. \\ Andersen $^{3}$, Dennis Strand ${ }^{1}$, Martin F. Sprinzl ${ }^{1}$, Susanne Strand ${ }^{1}$, Carolin Czauderna ${ }^{1}$, \\ Stefanie Heilmann-Heimbach ${ }^{4}$, Stephanie Roessler ${ }^{5}$, Arndt Weinmann ${ }^{1}$, Marcus A. \\ Wörns ${ }^{1}$, Snorri S. Thorgeirsson ${ }^{6}$, Peter R. Galle ${ }^{1}$, Matthias S. Matter ${ }^{7}$, Hauke Lang ${ }^{2}$ \\ and Jens U. Marquardt ${ }^{1}$ \\ 1 Department of Medicine, Johannes Gutenberg University, Mainz, Germany \\ 2 Department of Surgery, Johannes Gutenberg University, Mainz, Germany \\ ${ }^{3}$ Department of Health and Medical Science, Biotech Research and Innovation Centre, University of Copenhagen, Copenhagen, \\ Denmark \\ ${ }^{4}$ Department of Genomics, Institute of Human Genetics, Life \& Brain Center, University of Bonn, Bonn, Germany \\ ${ }^{5}$ Institute of Pathology, University Hospital Heidelberg, Heidelberg, Germany \\ ${ }^{6}$ Laboratory of Experimental Carcinogenesis, Center for Cancer Research, National Cancer Institute, NIH, Bethesda, MD, \\ USA \\ 7 Department of Pathology, University of Basel, Basel, Switzerland \\ * These authors have contributed equally to this work \\ Correspondence to: Jens U. Marquardt, email: marquarj@uni-mainz.de \\ Keywords: liver cancer, microenvironment, hepatocarcinogenesis, stemness features, field effect \\ Received: February 22, $2017 \quad$ Accepted: March 03, $2017 \quad$ Published: March 15, 2017
}

Copyright: Castven et al. This is an open-access article distributed under the terms of the Creative Commons Attribution License 3.0 (CC BY 3.0), which permits unrestricted use, distribution, and reproduction in any medium, provided the original author and source are credited.

\section{ABSTRACT}

Hepatocellular Carcinoma (HCC) commonly develops in chronically damaged liver tissues. The resulting regenerative and inflammatory processes create an adverse milieu that promotes tumor-initiation and progression. A better understanding of the hepatic tumor-microenvironment interaction might infer profound therapeutic implications.

Integrative whole genome and transcriptome analyses of different tumor regions, the invasive tumor border and tumor-surrounding liver $(\mathrm{SL})$ were performed to identify associated molecular alterations and integrated with our existing HCC database. Expression levels and localization of established CSC markers were assessed in preneoplastic lesions and confirmed in two independent patient cohorts using QRT-PCR, immunohistochemistry and immunofluorescence.

Our results indicate that genomic and transcriptomic profiles between SL and different tumor regions are quite distinct. Progressive increase in genetic alterations and activation of pathways related to proliferation as well as apoptosis were observed in the tumor tissue, while activation of stemness markers was present in cirrhotic SL and continuously decreased from pre-neoplastic lesions to HCC. Interestingly, the invasive tumor border was characterized by inflammatory and EMT-related gene sets as well as activation of pro-survival signaling. Consistently, integration of gene expression signatures with two independent HCC databases containing 300 HCCs revealed that border signatures are predictive of HCC patient survival.

Prognostic significance of the permissive liver microenvironment might be a consequence of a pro-oncogenic field effect that is caused by chronic regenerative processes. Activation of key oncogenic features and immune-response signaling indicates that the cross-talk between tumor and microenvironment might be a promising therapeutic and/or preventive target. 


\section{INTRODUCTION}

Hepatocellular carcinoma (HCC) ranks among the most common cancers worldwide [1]. In the vast majority of patients $\mathrm{HCC}$ develops on the basis of an underlying chronic liver disease, whereby the chronic liver damage induces subsequent regenerative and inflammatory processes [2]. A constant remodeling of the diseased liver parenchyma and activation of immune-cell mediated inflammation creates an adverse milieu that promotes HCC development [3]. As a result, a significant phenotypic and molecular heterogeneity is observed in $\mathrm{HCC}$ that hampers therapeutic progress and, to date, sorafenib remains the only approved therapy for advanced HCC [4].

It is well recognized that acquisition of preneoplastic (epi-)genetic alterations in the hepatic microenvironment induces a continuum of morphologic changes from chronic inflammatory cell death over cirrhosis to dysplastic lesions which promotes malignant transformation [5]. Intense cross-talk between cancer cells and stromal/immune cells further promotes HCC development and progression in the majority of HCCs [6]. Also, activation of pro-inflammatory cytokines (e.g. acquisition of autocrine IL6 signaling in hepatic progenitor cells) induces a broad range of effects on a variety of resident and non-resident cells (e.g. immune cells) and can be considered a key oncogenic driver in HCC development [7]. Consistently, we have demonstrated that activation of immune-related signaling pathways in dysplastic lesions and early HCC is important for the sequential evolution of liver cancer and precedes the acquisition of malignant features in progressed HCC [8]. Therefore, activation of molecular changes involved in inflammation as well as cancer should be considered in the pursue to identify novel therapeutic targets [3]. Importantly, activation of inflammation related gene-sets not only impairs the development of HCC, but possesses profound prognostic implications [9]. A recent study further showed that gene expression signatures generated from surrounding nontumor liver tissue could accurately predict the patient outcome in HCC, whereas signals from the tumor did not provide a meaningful clinical association [10].

Several immune response-related and prooncogenic molecules induce opposing effects when activated in diverse parenchymal and non-parenchymal cell types (e.g. immune cells versus hepatocytes) and during different states of the chronic liver disease (e.g. inflammation, fibrosis, cirrhosis) which underlines the critical importance of the interaction of signals from the microenvironment and the tumor cells for tumor initiation and progression $[11,12]$. Other aspects of the tumormicroenvironment cross talk are synergistic and amplify the malignant potential of the tumors [6]. Therapeutically, different cell types might augment the anti-cancer activity of sorafenib. Further, several studies clearly showed that pro-oncogenic changes in the hepatic microenvironment during chronic liver inflammation are orchestrated by the interaction of parenchymal cells with diverse types of non-parenchymal cells $[5,13]$. Therefore, a better understanding of the tumor-microenvironment interaction might open therapeutic options [14]. In the here presented study, we analyzed the genome and transcriptome profiles of tumor tissue, the invasive tumor margin and peritumoral liver tissue of HCC patients from a Western cohort. Our results demonstrate that the hepatic microenvironment is critical for malignant progression of HCC. While genetic alterations continuously increased from the peritumoral tissue to the tumor core, prognostic adverse transcriptomic signals and stemness features were activated in the invasive tumor margin of the tumor surrounding liver tissue. These observations suggest that the chronic inflammation creates a pro-oncogenic field effect and should be considered a hallmark of liver cancer.

\section{RESULTS}

\section{Characterization of the molecular profiles in different tumor regions}

The importance of the chronic inflammatory liver diseases for HCC initiation and progression has been repeatedly demonstrated [5]. To characterize in more detail the cross-talk between tumor cells and the diseased microenvironment and define key molecular mechanisms leading to cancer progression, we macroscopically dissected non-neoplastic tumor-surrounding liver tissue (SL) from the invasive tumor margin/ border (B) as well as the core tumor tissue (T). First, we assessed the global transcriptome profiles for each of the regions. As expected, the highest number of differentially expressed genes was found between T and SL (2630 genes), followed by B $v s$ SL (590 genes) (Supplementary Table S3). Transcriptomic profiles of $\mathrm{T}$ and $\mathrm{B}$ showed the highest similarity and only 100 genes showed significant differences (Figure 1A). The identified gene expression signatures significantly separated the different regions, thus validating that the genes effectively stratify for each region (Figure 1B). Not unexpectedly, subsequent pathway analysis using GeneGo and IPA showed enrichment of genes related to pro-proliferative signaling and DNA damage response (CCND1, CD4, ABCC4, APEX1, MAPK9, BMI1, MAT1A, MLH1, FADD, FOS, PIK3R1, FOS, RAD51C, $X R C C 3$ ) for the $\mathrm{T} v s \mathrm{SL}$ as well as B vs SL signatures (Supplementary Table S4). Furthermore, both the T vs B and B vs SL signature showed activation of functional networks related to immune response, inflammation and IL-6 signaling (CXCL12, CUL1, CDK5, CD82, PIK3R1, SMARCA4, ESR1, IKBKG, SPP1, IL17RA, EGR1, $I G F 1, I G F B P 1, I F N A R 1$ ), confirming the crucial role of chronic inflammation and related molecular pathways 
A)

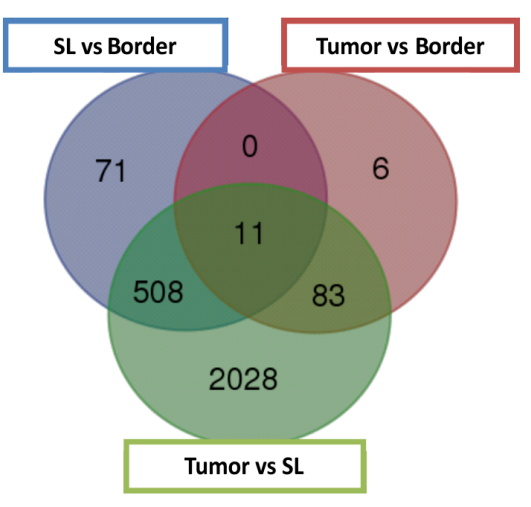

C)
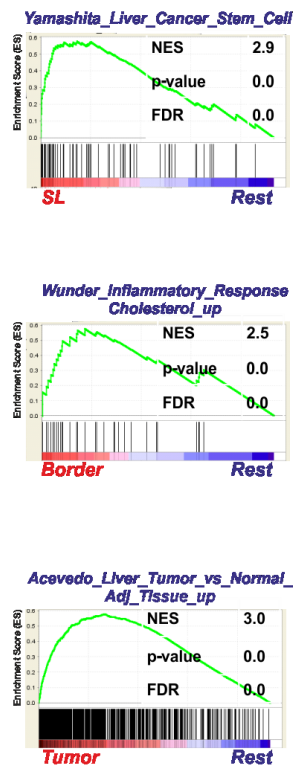

\section{Surrounding liver}

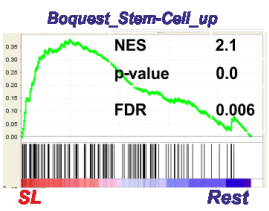

\section{Border}

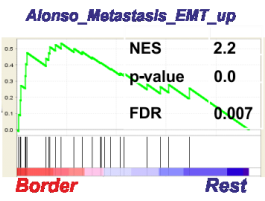

\section{Tumor}

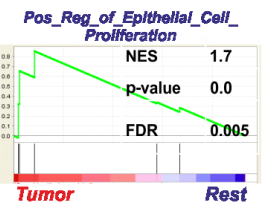

B)
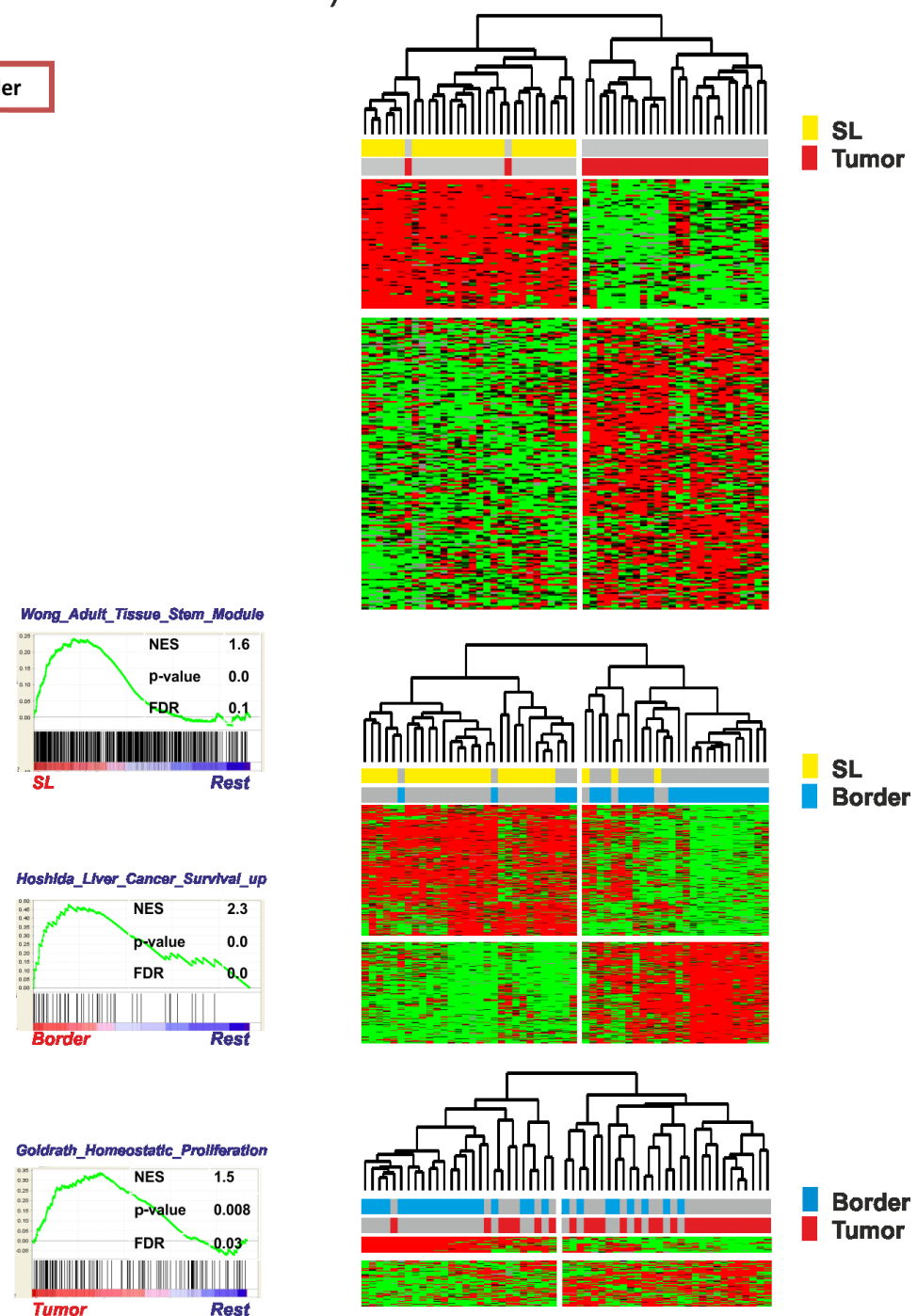
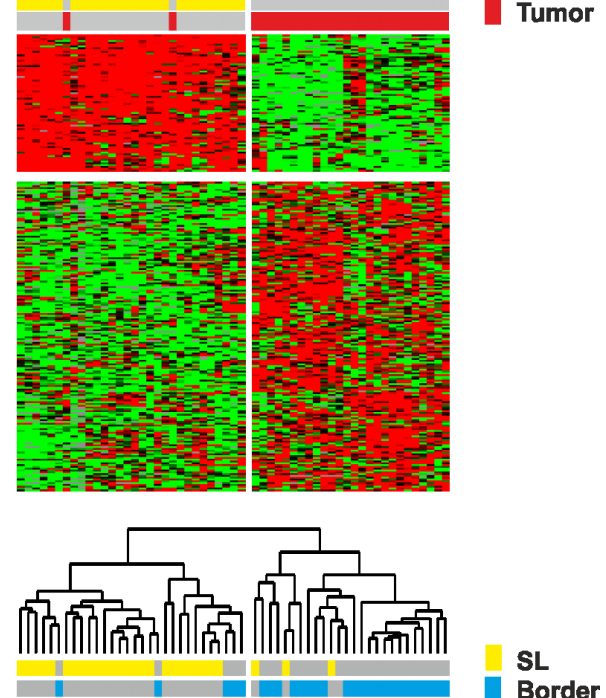

Border
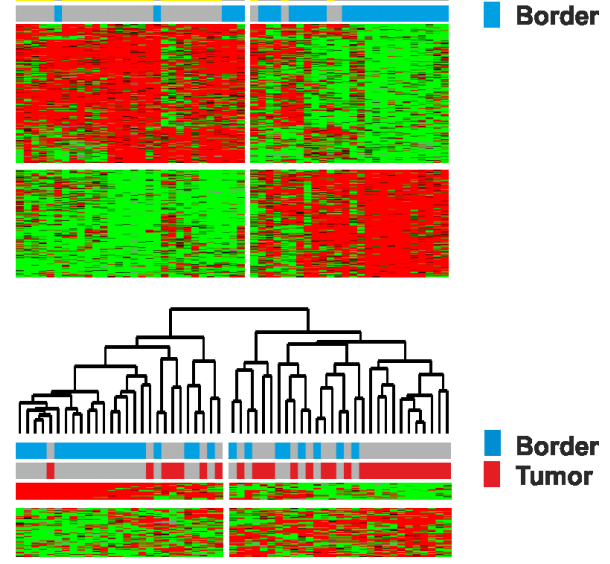

D)

Chrom. $2,3,4,4$

$S L$ 5, 7

Border

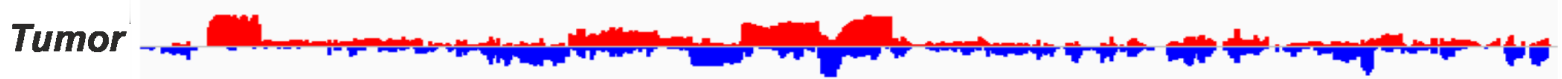

Figure 1: Transcriptomic and genomic profiles of the different regions. A. Venn diagram demonstrating the overlap between the different gene expression signatures. B. Unsupervised hierarchical cluster analysis of the different regions based on the corresponding significant genes (SL $v s$ tumor (2630 genes): upper panel; SL $v s$ border (590 genes): middle panel; border $v s$ tumor (100 genes): lower panel) C. Gene set enrichment analysis (GSEA) for each of the regions in comparison to all other regions (rest). Normalized enrichment score (NES) reflects degree of overrepresentation for each group at the peak of the entire set. Statistical significance calculated by nominal $P$ value of the ES by using an empirical phenotype-based permutation test. D. Graphical representation of the genetic alterations in each region determined by DNAcopy. Amplifications are depicted and red and losses are depicted in blue. 
for hepatocarcinogenesis [7]. Additionally, molecules related to adverse and pro-metastatic features were also highly activated/repressed in the invasive tumor margin (CDH1, ABCG5, APOA1, ID2, LAMC1, CTNNA1, MGMT, $H N F 4 A, A L D H 8 A)$. Next, gene set enrichment analysis (GSEA) was performed to delineate the activated gene sets characteristic for each region. GSEA confirmed the activation of genes involved in pro-oncogenic signaling and proliferation in the $\mathrm{T}$ region (Figure $1 \mathrm{C}$; lower panel) as well as inflammation in the $\mathrm{B}$ region (middle panel). Further, enrichment of gene sets commonly associated with EMT, metastatic traits as well as survival was observed for the $\mathrm{B}$ region, indicating a potential association to the outcome of HCC patients. Interestingly, GSEA revealed an abundance of gene sets associated with (cancer-) stemness in SL regions (Figure 1C; upper panel). These results indicate that the tumor margin (B) is enriched in inflammatory gene sets and shows activation of adverse signaling pathways, while tumor tissues mainly show activation of proliferative genes. Further, our results indicate that the hepatic microenvironment contributes to a stemness phenotype observed in many human HCCs.

We next assessed the somatic genetic alterations present in the different regions by profiling the corresponding tissues using Illumina OmniExpress arrays followed by GISTIC 2.0 analyses. Overall, progression from SL to $\mathrm{T}$ showed a continuous increase in genetic alterations (Figure 1D; Supplementary Figure $\mathrm{S} 2$ ). As expected, recurrent changes of $\mathrm{B}$ and $\mathrm{T}$ regions involved gains in $1 \mathrm{q}$ and $8 \mathrm{q}$ as well as copy number losses in 8p (Figure 1D) [15]. GISTIC analyses based on corresponding SL further identified 15 and 8 significantly reoccurring focal amplifications in $\mathrm{T}$ and $\mathrm{B}$ regions, respectively (Supplementary Table S3). Notably, the only commonly amplified regions in $\mathrm{T}$ and $\mathrm{B}$ involved 7q11.21 while other well characterized driver oncogenes such as hTERT (5p15.33) were only observed in tumors. Among 30 deletion events in T and 39 in B regions, PTX4 (16p13.3), KIF20B (10q23.31), SYCP2 (20q13.33) and 9p21.3 (CDKN2A and CDKN2B, MTAP) were prominent in both $\mathrm{T}$ and $\mathrm{B}$. These results confirm that alterations of the genome play a central role for tumor cell proliferation in $\mathrm{T}$ and B. Further, transcriptome changes observed in SL might be predominantly driven by other mechanisms (e.g. epigenetics) and potentially induced by the chronic inflammation as well as the tumor-microenvironment cross-talk.

\section{Activation of pro-proliferative gene sets in the tumors}

Our molecular analyses indicated a predominant activation of proliferative signaling in the $\mathrm{T}$ region that

\section{A)}

\section{Proliferation}
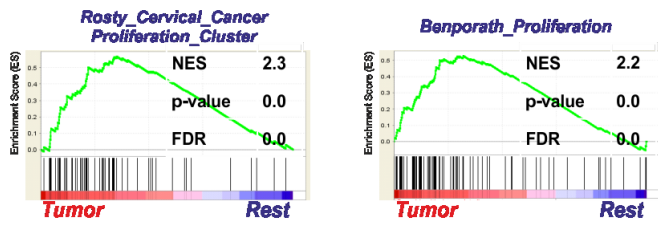

B)
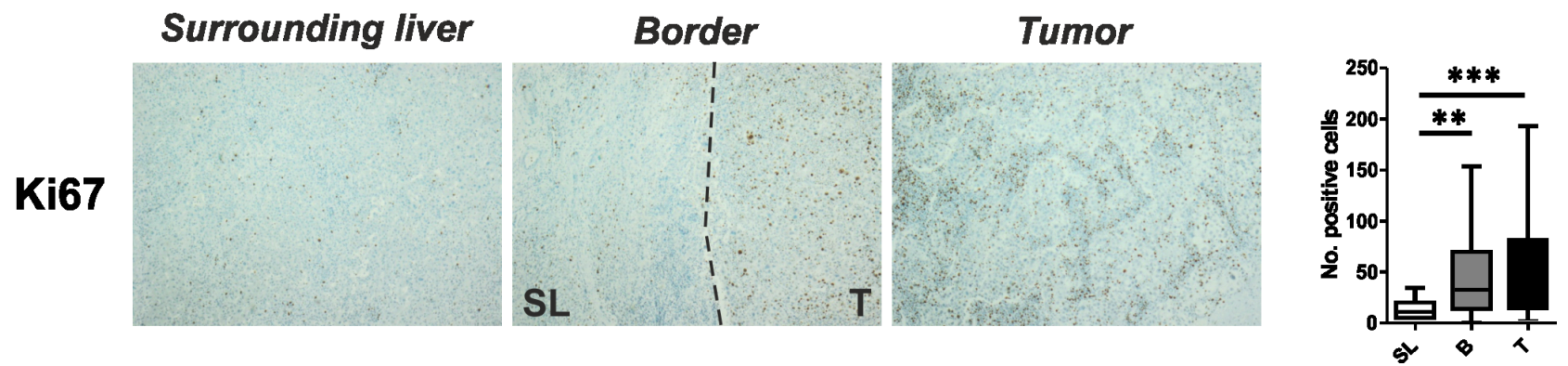

Figure 2: Activation of proliferation in tumor tissues. A. Gene set enrichment analysis (GSEA) of the tumor regions in comparison to all other regions (rest) indicate an activation of proliferative gene sets. Normalized enrichment score (NES) reflects degree of overrepresentation for each group at the peak of the entire set. Statistical significance calculated by nominal $P$ value of the ES by using an empirical phenotype-based permutation test. B. Proliferation of cells determined by Ki67 staining. Dashed bars indicating the separation between SL and T regions. Right panel shows the graphical representation as number of positive cells estimated based on 10 randomly selected view fields (20x magnification). Statistical evaluation based on Friedman- test for multiple group comparisons followed by Dunns posthoc test. $(n=22$; P-values: $* \leq 0.05 ; * * \leq 0.05 ; * * \leq 0.001)$. The data are presented as mean fold differences $\pm \mathrm{SD}$. 
might reflect tumor cell proliferation thereby potentially supporting tumor expansion. Extension of the GSEA for the $\mathrm{T}$ region confirmed this finding and demonstrated an enrichment of gene sets associated with deregulation of cellular genes particularly related to tumor cell proliferation in cervical cancer [16] as well as genes generally associated with proliferation [17] in this region (Figure 2A). Notably, despite the proliferative potential of these genes and frequent activation in cancer, no association to the outcome of patients could be established suggesting that the high proliferation observed in many solid tumors might not necessarily confer to prognostic traits [17]. To confirm that the activation of proliferation genes indeed confers to proliferation in the tumors, specimens were stained for Ki67 expression (Figure 2B). As expected, significantly higher Ki67 levels were observed in $\mathrm{T}$ and $\mathrm{B}$ in comparison to SL. Notably, although proliferation of cells in $\mathrm{T}$ was generally highest, expression levels did not significantly differ to those observed in the B regions (Figure $2 \mathrm{~B}$ ).

\section{Activation of stemness in the peritumoral tissue}

Since our molecular analyses indicated an activation of stemness in the SL region, we next assessed the gene expression levels of specific $\mathrm{HCC} /$ differentiation markers (AFP, GPC3, albumin) as well as the selected (cancer-) stemness markers (EpCAM, CD133, CK19) and pluripotency genes (NANOG). As expected, a strong activation in expression levels of AFP and GPC3 as well as a concomitant downregulation of albumin levels were observed from SL to T (Figure 3A; Supplementary Figure S3). Notably, expression of AFP was generally low and undetectable by qRT-PCR in the majority of cases. Consistently, levels of the stemness and pluripotency markers showed a significant decrease from SL to T (Figure 3A; Supplementary Figure S3). Of note, expression of well-known progenitor cell marker CK19 was highest in peritumoral tissue and almost absent in tumor tissue [18]. However, two of the investigated tumors showed a high positivity leading to a high variability and explaining the missing statistical significance between SL and T (Figure 3A). Results for AFP, GPC3 and EpCAM could further be validated in an independent validation cohort of HCC patients as well as cirrhotic livers without HCCs (Supplementary Figure S4, Table 1B). Importantly, activation of EpCAM did not show significant differences in cirrhotic livers in the absence of HCC, confirming that induction of EpCAM positive cells in the tumorsurrounding liver is predominantly seen in the context of hepatocarcinogenesis (Supplementary Figure S4). Interestingly, similar results could also be revealed during sequential evolution of liver cancer (Supplementary Figure S5). RNA sequencing in patients with synchronous co-existence of pre-neoplastic lesions as well as HCC confirmed a continuous decrease in stemness genes from SL over dysplastic lesions to progressed HCC.

To confirm that the diseased hepatic tumor microenvironment is the critical determinant of stemness activation, we next assessed expression levels of the stemness genes in livers containing metastasis from different primaries $(n=5)$. Importantly, we found that these markers were not induced in the non-diseased liver tissue (i.e. in the absence of chronic liver damage) (Figure 3B, Supplementary Figure S6). However, consistent with an aggressive phenotype of metastases, high levels of the markers were detected in metastatic cells (Figure 3B; Supplementary Figure S6). Together, these results corroborate that the hepatic microenvironment plays a crucial importance for the acquisition of stemness traits in $\mathrm{HCC}$.

\section{Activation of immune cells in the invasive tumor border}

To confirm the activation of inflammatory gene sets and dissect the corresponding immune cells reflected by the molecular changes, we limited our GSEA query to gene sets with association to immune-related properties. We observed a significant enrichment of gene sets related to alternative M2 macrophage activation that might exert pro-tumorigenic function (Figure 4A). Furthermore, molecular signals resembling non-hypoxic macrophages that display impaired anti-tumor response were enriched in B regions which might further decrease the immune response and promote immune escape of HCCs. Consistently, a significant increase of CD68 could be demonstrated in $\mathrm{B}$ vs $\mathrm{T}$ regions (Figure 4B; upper panel). Additionally, gene sets associated with activated tumor-infiltrating CD8 T cells were enriched in the B regions. However, we also recognized activation of genes indicative of PD-1 function commonly associated with exhaustion anti-tumoral $\mathrm{T}$ cell function and properties, potentially resulting in impaired immune-surveillance. Consistently, we observed a significantly higher number of CD3-T cells as well as increased PD-1 expression in the SL and B region compared to T (Figure 4B). Together, these results highlight the importance of immunerelated mechanisms in the invasive $\mathrm{B}$ region for tumor progression.

\section{The invasive tumor border is important for $\mathrm{HCC}$ patient outcome}

Finally, we tested the clinical significance of our identified SL, B and T signatures and integrated all three signatures with our previously published gene expression dataset of 53 human HCC. [19] Subsequent KaplanMeier analysis showed that, despite the high proliferative 
A)
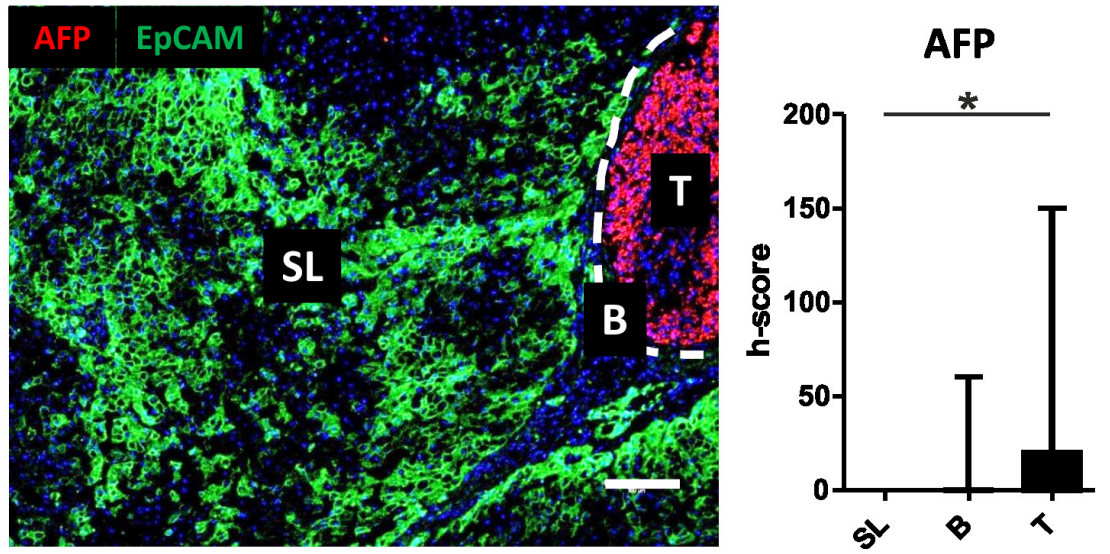

\section{EPCAM}
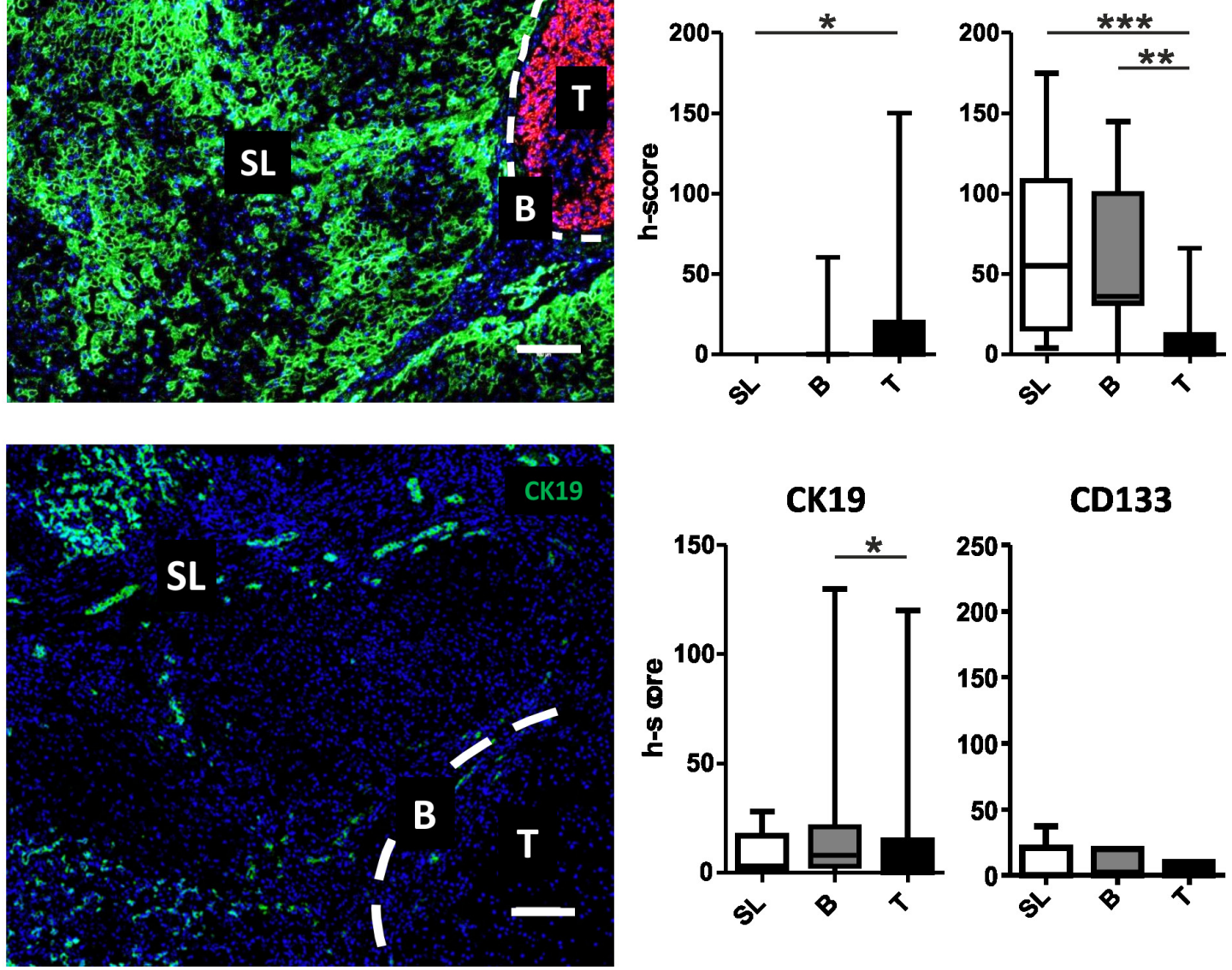

B)
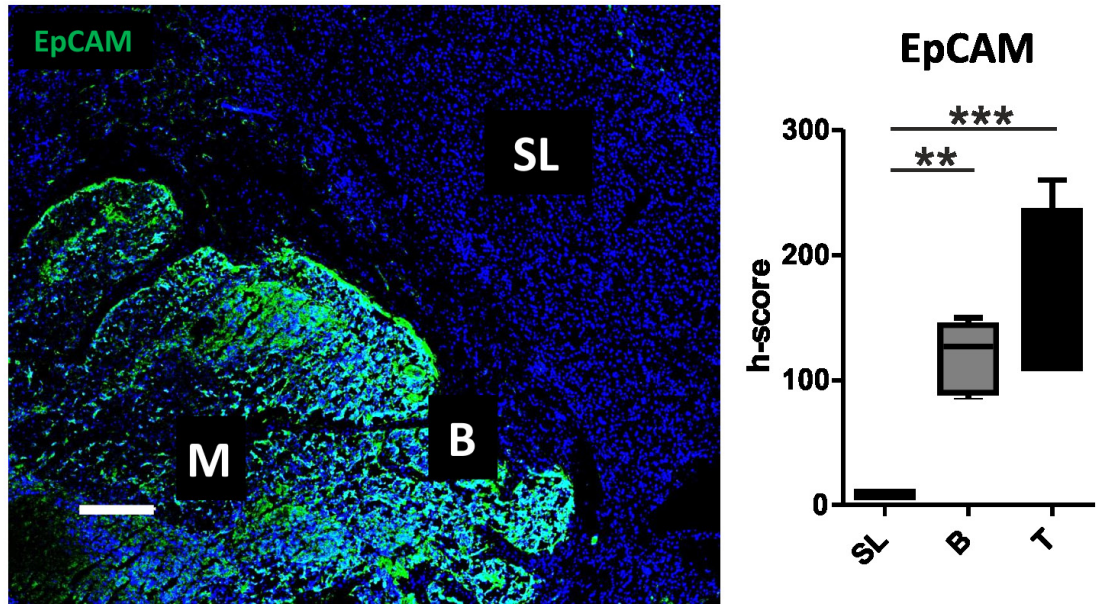

Figure 3: Activation of stemness markers in peritumoral tissues. A. Activation of stemness marker in the different regions was determined by confocal imaging. Representative images for AFP (red) and EpCAM (green) staining (upper panel) and CK19 (lower panel) containing all different regions $(\mathrm{T}=$ tumor, $\mathrm{B}=$ border, $\mathrm{SL}=$ surrounding liver $)$ are displayed. Dashed bars indicating the separation between SL and T regions. White bar representing $100 \mu \mathrm{m}$. Graphical representation and statistical evaluation (right graphs) for each marker based on h-score and Friedman- test for multiple group comparisons followed by Dunns posthoc test. $(n=15$; P-values: * $\leq 0.05$; $* * \leq$ $0.05 ; * * * \leq 0.001$ ). The data are presented as mean fold differences \pm SD. B. Activation of stemness marker EpCAM (green) by confocal microscopy. Images contains representation of all different regions $(\mathrm{M}=$ metastasis, $\mathrm{B}=$ border, $\mathrm{SL}=$ surrounding liver). White bar representing $200 \mu \mathrm{m}$. Graphical representation and statistical evaluation (right graphs) for each marker based on h-score and Friedman- test for multiple group comparisons followed by Dunns posthoc test. $(n=5$; P-values: $* \leq 0.05 ; * * \leq 0.05 ; * * \leq 0.001)$. The data are presented as mean fold differences $\pm \mathrm{SD}$. 
A)

Macrophage activation
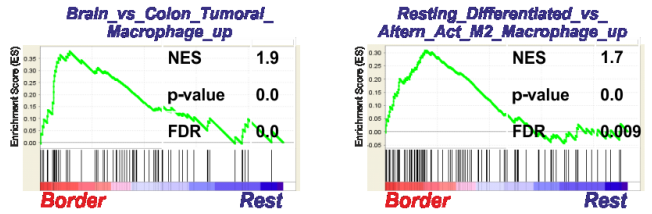

T-cell activation/function
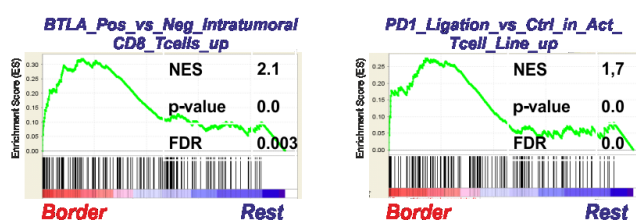

B)

H\&E

CD3
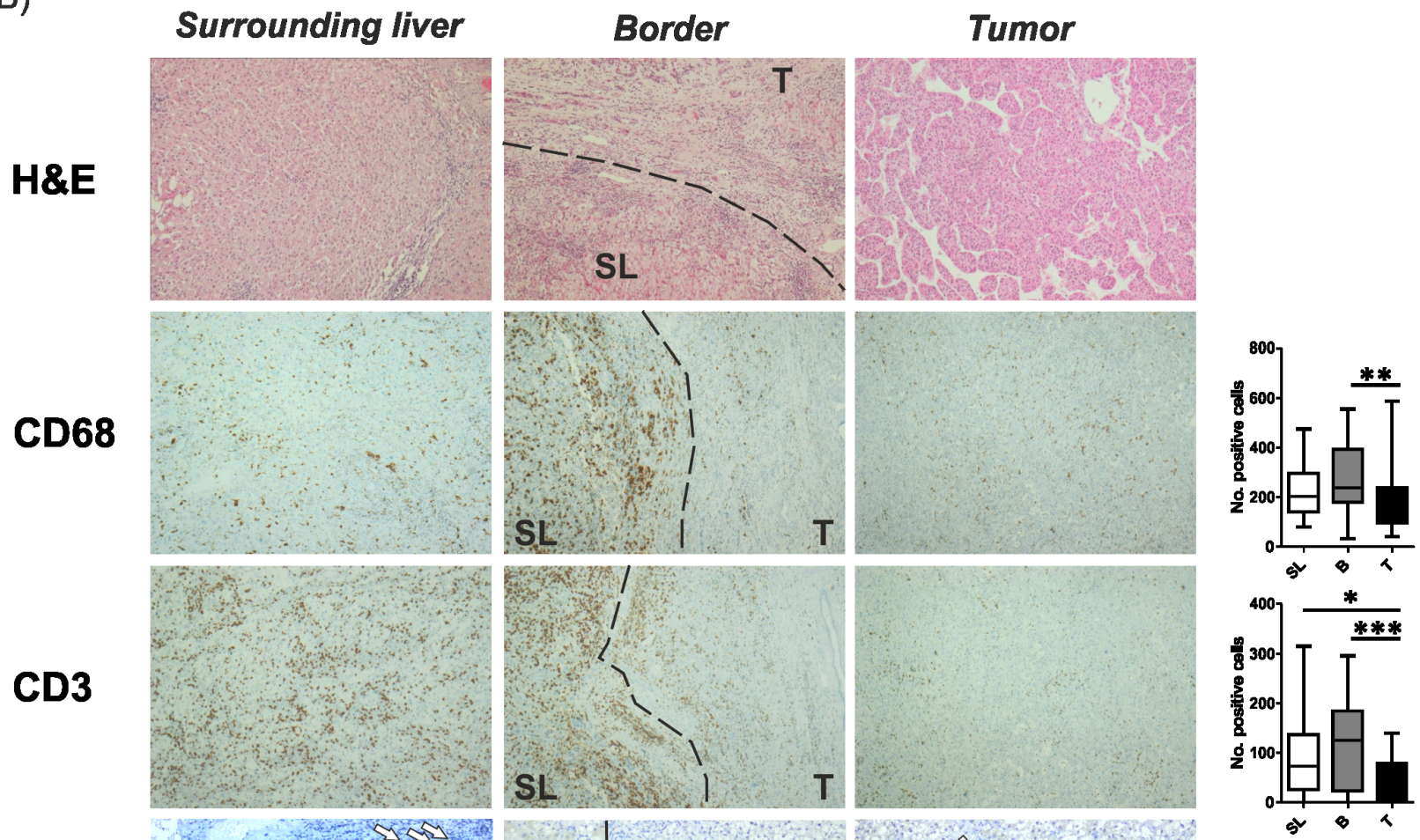

PD-1
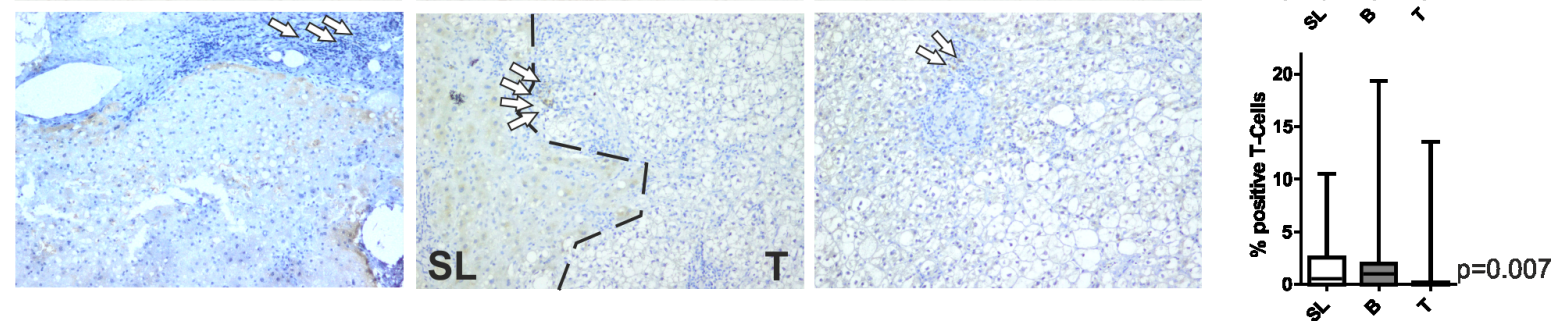

Figure 4: Activation of inflammatory gene sets and immune cells in the invasive tumor margin. A. Gene set enrichment analysis (GSEA) of the surrounding liver regions in comparison to all other regions (rest) indicate an activation of gene sets involved in macrophage as well as T cell activation/function. Normalized enrichment score (NES) reflects degree of overrepresentation for each group at the peak of the entire set. Statistical significance calculated by nominal $P$ value of the ES by using an empirical phenotypebased permutation test. B. Representative H\&E stainings are shown in the upper graph. Immunohistochemistry of CD68 and CD3 demonstrating activated macrophages and $\mathrm{T}$ cells. Lower panel shows representative images of PD-1 staining reflecting impaired $\mathrm{T}$ cell function. Dashed bars indicating the separation between SL and T regions. White arrows indicating selected positive cells. Right panels show the corresponding graphical representations as number of positive cells estimated based on 10 randomly selected view fields $(20 \mathrm{x}$ magnification). Statistical evaluation based on Friedman- test for multiple group comparisons followed by Dunns posthoc test. ( $n=22$; P-values: $* \leq 0.05 ; * * \leq 0.05 ; * * * \leq 0.001)$. 
activity, the T vs SL signature did not possess prognostic significance (Figure 5A). However, both the B vs SL and $\mathrm{B} v s \mathrm{~T}$ signatures independently classified $\mathrm{HCC}$ patients according to survival (Figure $5 \mathrm{~B}$ and $5 \mathrm{C}$ ). The prognostic impact of both signatures could further be confirmed in an independent cohort from $247 \mathrm{HCC}$ patients (Supplementary Figure S7). Overall, the prognostic impact of signatures derived from signals of the B region underlines the clinical importance of the invasive tumorfront that might be helpful to identify novel therapeutic targets.

\section{DISCUSSION}

The notion that HCC patients display two diseases that are inextricably linked to each other, i.e. a chronic liver disease and a malignant tumor, is increasingly recognized, whereby the diseased hepatic microenvironment significantly promotes cancer initiation and progression while concomitantly limiting aggressive therapeutic approaches [20]. Therefore, the importance of the chronic inflammatory liver disease can be considered a hallmark feature of HCC and has become focus of intense research $[3,21]$. We here provide evidence that chronic changes of the liver microenvironment induce an adverse pro-oncogenic niche that might lead to the activation of stemness features and pre-dispose to liver cancer development. Heterogeneous patterns of molecular alterations present in tumor surrounding liver tissue suggest that a potential field cancerization might significantly contribute to hepatocarcinogenesis [22]. Further, our transcriptome analyses indicate that the cross-talk between the inflammatory microenvironment and the tumor cells in the invasive tumor border might be an important determinant of the patient prognosis while tumor cell growth is mainly driven by proliferative signaling induced in the tumors.

To address the importance of distinct peritumoral and tumoral regions for hepatocarcinogenesis we analyzed the molecular profiles of tumor-surrounding liver tissue, the invasive tumor border and core tumor tissue by genome-wide approaches and at different molecular levels. The transcriptome analyses confirmed a distinct gene expression profile for each of the different regions (Figure 1). As expected, most abundant differences were observed between $\mathrm{T}$ and SL regions and mainly centered around functional networks involved in tumor cell proliferation as a key feature of tumor expansion [23]. Consistently, the tumor region showed the highest amount of cycling cells (Figure 2B). Concomitantly, most significant genetic alterations were also observed in $\mathrm{T}$ regions and involved known driver genes of hepatocarcinogenesis such as hTERT and CDKN2A and CDKN2B [24, 25]. An interesting observation is the activation of stemness gene sets and pathways as well as established (cancer-) stemness markers in the tumor surrounding liver tissue as well as the invasive B region (Figure 3; Supplementary Figure S3) $[26,27]$. The notion that the acquisition of stemness is an important characteristic of malignant transformation is well recognized and expansion of cells that display progenitor cell features is frequently observed in the majority of chronic liver diseases [2, 28, 29]. A recent study further utilized a monoclonal antibody against 1B50-1 to detect a population of cells with CSC properties in human HCCs [30]. In concordance with our findings, these CSCs were located in the surgical margins of primary $\mathrm{HCC}$ and possessed prognostic as well as therapeutic implications. Our results, therefore, support the hypothesis that the permissive hepatic microenvironment induces a pro-oncogenic field effect which activates stemness traits and ultimately promotes tumor development and progression $[22,31,32]$. The relatively low number of genetic alterations such as copy-number changes further suggests that gene expression changes in the SL region are mainly driven by other mechanisms, e.g. epigenetic mechanisms, which might support the concept of an epigenetic progenitor cell origin in HCC that is induced by the chronic inflammatory liver disease [33]. Notably, whether the cellular origin of the cells resembles hepatocytes or stem progenitor cells remains uncertain $[7,34,35]$. Although the decrease in stemness markers during sequential hepatocarcinogenesis from SL over dysplastic lesions to established HCCs (Supplementary Figure S5) favors the hypothesis that these cells contribute to tumor development, invasion of stem-like cancer cells from the tumor as a reflection of malignant progression cannot be excluded $[36,37]$. Our analyses also suggest that, while the proliferative properties were predominantly acquired by tumor cells in the T region, B and SL show additional activation of immune-related and pro-metastatic signaling. Activation of inflammatory gene sets in tumorsurrounding liver tissue is a hallmark feature of HCC and associated with a poor clinical outcome [10]. Consistently, a significantly higher number of both macrophages and $\mathrm{T}$ cells was seen in SL and $\mathrm{B}$ regions compared to $\mathrm{T}$ regions (Figure 4). Despite several reports that show differences in the (immune-)cellular composition in the $\mathrm{B}$ and SL regions, a recent study also confirmed a potential therapeutic impact of this region [38]. Treatment with sorafenib induced significant changes to the HCC microenvironment by affecting macrophage polarization and inhibited accumulation of adverse M2 polarized tumor-associated macrophages at the tumor margin or within the peritumoral area. We also observed an increased number of CD3 T cells in the SL and B region, a feature that is commonly associated with an increased tumorcell clearance and favorable outcome [39]. However, the dominant activation of T cells with enrichment for PD-1 function suggest that these cells might display impaired antitumor activity thereby leading to evasion of tumorimmuno-surveillance and poor outcome [40-42]. Notably, activation of check-point genes such as PD-1/PDL-1 and 
A) Surrounding liver vs tumor signature
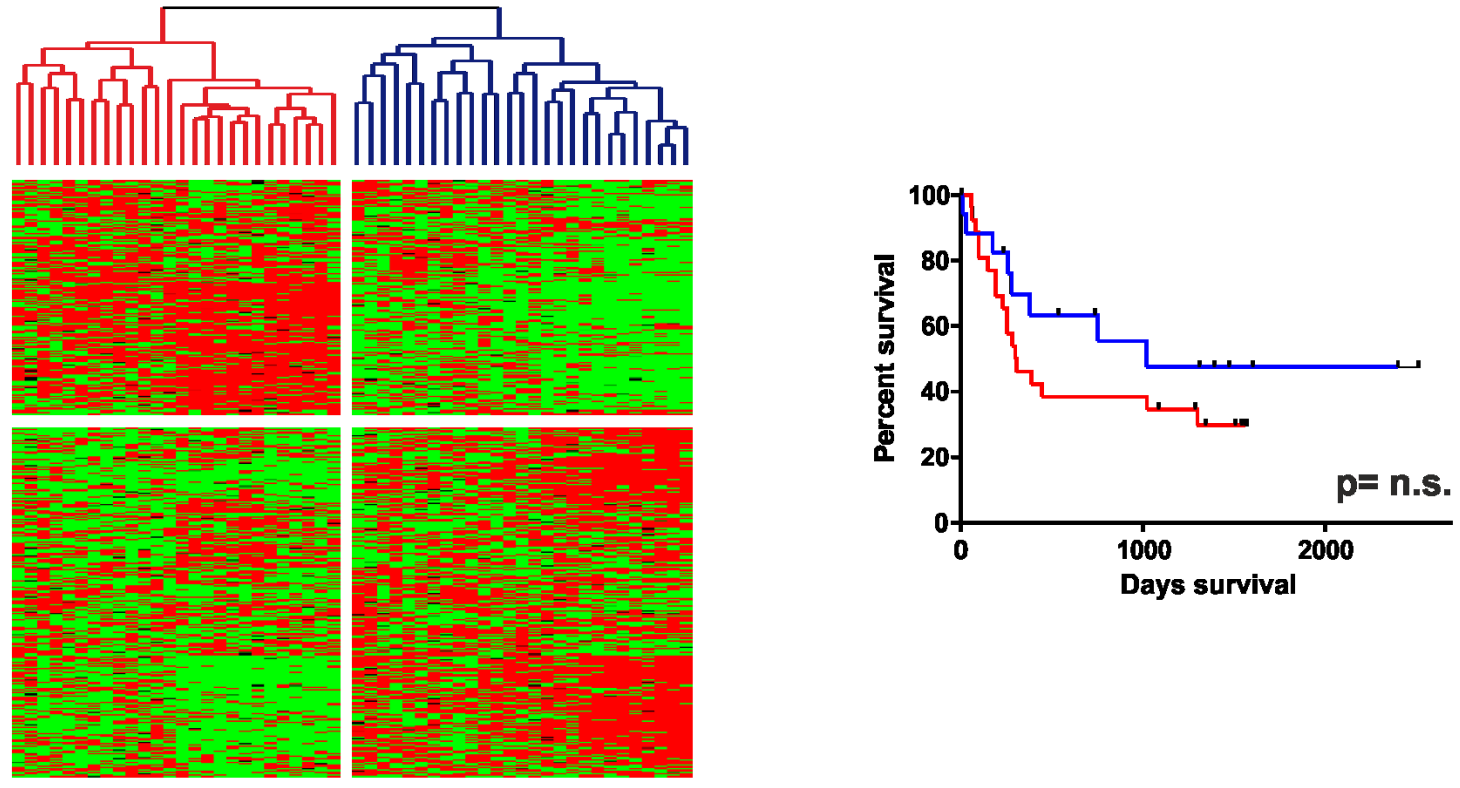

+ Cluster 1

+ Cluster 2

B)

Surrounding liver vs border signature
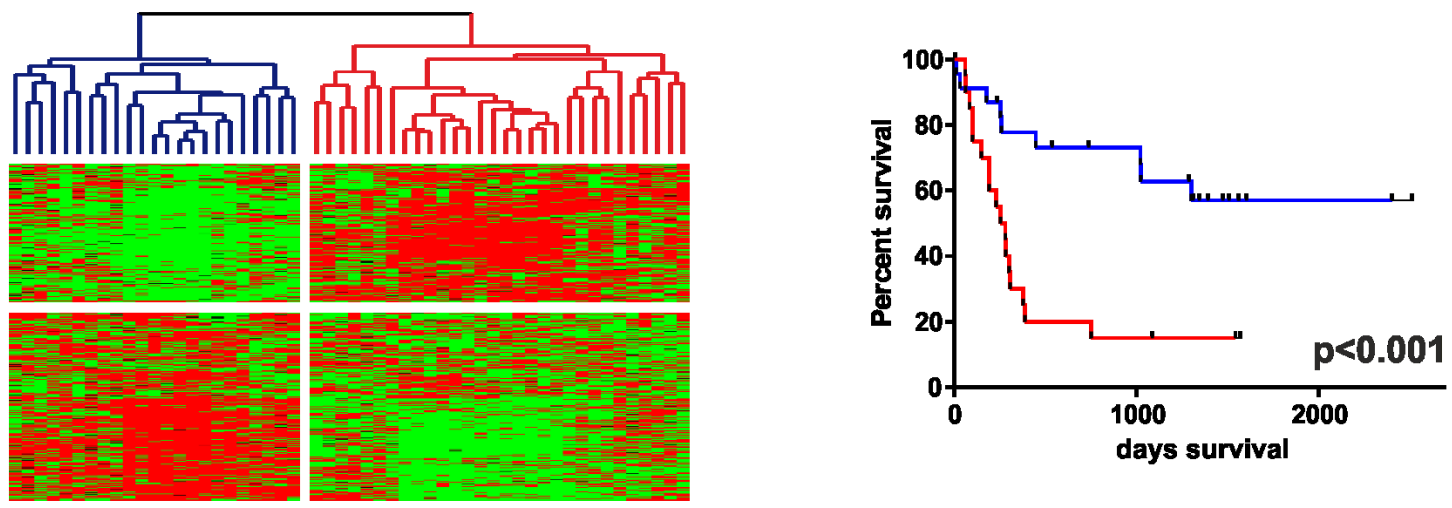

+ Cluster 1

+ Cluster 2

C)

Border vs tumor signature
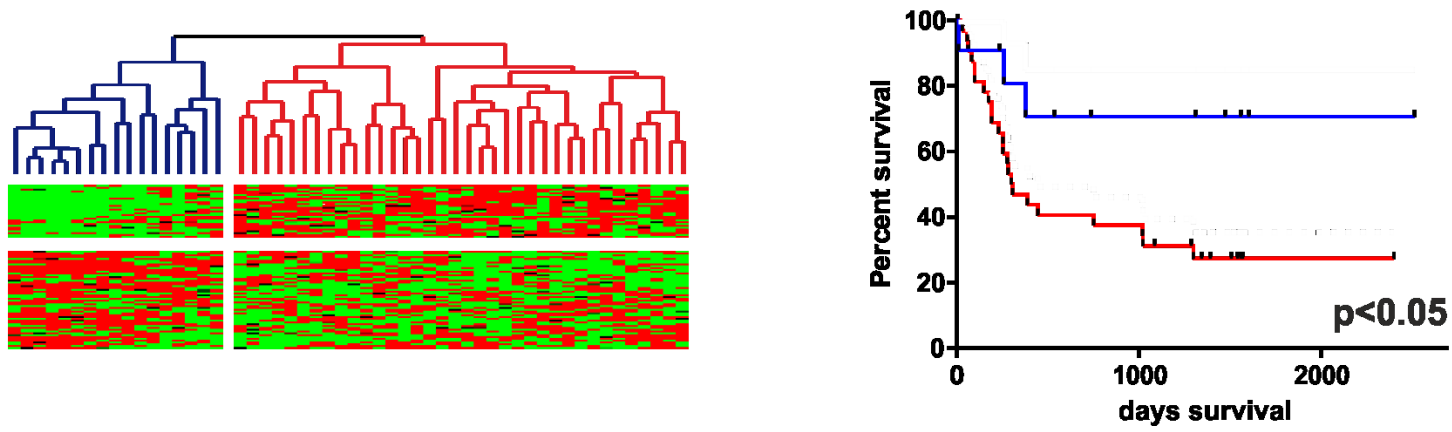

- Cluster 1

+ Cluster 2

Figure 5: Prognostic implications of the identified gene expression signatures. Integration of the different gene expression signatures with our previously published dataset of 53 HCC patients [19]. Unsupervised cluster analyses (left) and Kaplan-Meier plots of overall survival (right) for each of the identified signatures are shown: A. SL vs tumor (2630 genes): upper panel; B. SL vs border (590 genes): middle panel; C. border vs tumor (100 genes): lower panel). 
CTLA4 could be linked to a poor clinical outcome in HCC $[40,41]$. Therefore, results of our study owes to the promise of immunotherapeutic approaches for liver cancer [43]. Importantly, the design of our study does not allow the prediction which of the individual patients will show a favorable or adverse outcome. Therefore, the activation of adverse signaling pathways and putative prognostic implications within the B regions are strictly associative. Since several reports suggest that infiltrating CD8 T-cells in the tumor border might also confer to a favorable outcome [39], these observations clearly require a detailed functional validation as well as individual confirmative analyses. Nevertheless, our results demonstrate a therapeutic and prognostic importance of the tumor/liver border which is not assessed in the current clinical routine (e.g. histology). Our results, therefore, suggest that novel diagnostic strategies should include the molecular and histological evaluation of the invasive tumor border. In line with this, integration of our transcriptome signatures with two independent cohorts of HCC patients clearly confirmed that the activation of inflammatory and adverse signaling pathways in the $\mathrm{B}$ regions has a strong association with the outcome of HCC patients (Figure 5; Supplementary Figure S7) [15, 19]. Together, the here presented results provide a detailed molecular and phenotypic characterization of the different peritumoral, border as well tumor regions and highlight the critical importance of the diseased hepatic microenvironment for HCC initiation and progression. The indicated prognostic significance of the cross-talk between tumor cells and microenvironment further underlines the recent success of immune check-point inhibitors in HCC and makes HCC a prime target for immunotherapeutic interventions [43].

\section{MATERIALS AND METHODS}

\section{Patient data and nucleic acid extraction}

Tissue from 28 patients with confirmed HCC undergoing resection at the Department of Surgery, University of Mainz, Germany were collected following patient informed consent and local ethics committee approval. Validation cohort of 20 patients was obtained from the Institute of Pathology, University of Basel, Switzerland. Clinicopatholigical details are provided in Supplementary Table S1. Tissue was macroscopically dissected into tumor tissue (T), tumor margin/ border (B) (approximately $2-4 \mathrm{~mm}$ from each region) and peritumoral tissue (SL) (Supplementary Figure S1). Total RNA was extracted using the Qiagen RNEasy mini Kit (Qiagen GMBH, Hilden, Germany) following the manufacturer's instructions. RNA quantity and purity were estimated using a Nanodrop ND-1000 Spectrophotometer (NanoDrop Technologies, Wilmington, DE), and integrity was assessed by Agilent 2100 Bioanalyzer (Agilent, Palo
Alto, CA). DNA was extracted using Qiagen Qiamp DNA Kit (Qiagen GMBH, Hilden, Germany) following the manufacturer's instructions.

\section{Gene expression analysis}

A total of $200 \mathrm{ng}$ RNA was linearly amplified as recommended by the manufacturer (Ambion, Austin, TX) and analyses were performed as described before [44]. The microarray datasets have been deposited to Gene Expression Omnibus database (http://www.ncbi.nlm.nih. gov/geo, accession number: GSE84598). Details of the analyses are provided in the Supplementary materials and methods.

\section{Immunohistochemistry and confocal microscopy}

Diagnosis of HCC was established by expert pathologists. Tissue was either fixed in $4 \%$ formaldehyde and embedded in paraffin or preserved for cryosections and cut in 3-5 $\mu \mathrm{m}$ sections. Antibodies and conditions for fluorescence and immunohistochemical staining are listed in Supplementary Table S2. Fluorescently stained tissues were viewed by a Zeiss LSM 710 NLO confocal microscope with $25 \mathrm{x}$ magnification objective and Tile Scan function. Quantification was performed using $\mathrm{H}$-score. H-score was determined based on the intensity of the staining (0-3) and percent of the positive cells $(0-100 \%)$ in a fixed view field. H-score was calculated using the next formula: H-score $=1 \mathrm{x}(\%$ cells with score $1)+2 x(\%$ cells with score 2$)+3 x(\%$ cells with score 3$)$. Immunohistochemistry was performed by automated immunostaining with iVIEW DAB detection kit (Ventana Medical System, Roche, Mannheim, Germany) according to the company's protocols. Monoclonal anti-CD68 (dilution 1:70, DakoCytomation), Ki67 antibodies (dilution 1:200, Rockland) and anti-CD3 antibodies (dilution 1:100, Santa Cruz) were used. Anti-EpCAM antibodies (dilution 1:80, Cell Signaling), anti-GPC3 antibodies (dilution as given by provider, Ventana Medical System, Roche, Basel, Switzerland), anti-AFP antibodies (dilution 1:400, DakoCytomation) were used. Stained tissues were viewed by a Zeiss Axioskop 2 plus microscope with 20x magnification objective and further analyzed in L.P. Optimas 6.51 software (Media Cybernetics). Number of positive cells was estimated in ten randomly chosen view fields. All quantifications were performed in triplicates.

\section{Statistics, databases and patient integration}

Statistical analysis was performed using Student's $t$-test, Friedman- test for multiple group comparisons followed by Dunns posthoc test as indicated. $P$-values $\leq 0.05$ were considered statistically significant. Results are 
presented as means $\pm \mathrm{SD}$ or means $\pm \mathrm{SEM}$ as indicated. Survival analyses were performed using log rank (MantelCox) tests.

\section{ACKNOWLEDGMENTS}

J.U.M. is supported by grants from the German Research Foundation (MA 4443/2-2), the German Cancer Aid (DKH 110989) and the Volkswagen Foundation (Lichtenberg program). J.U.M. thanks Monika Herr for excellent technical support. Aspects of this article are part of the doctoral thesis of Michael Fischer and Darko Castven.

\section{CONFLICTS OF INTEREST}

The authors have no conflict of interest.

\section{Author contributions}

Designed the experiments: JUM, MF, DC; Performed the experiments: JUM, DC, MF, JBA, MSM, SH, HL, CC, DS, SS, MFS, MW; Analyzed the data: DC, MF, SH, DB, PRG, JBA, AW, SST; Wrote the paper: JUM. All authors discussed the results and critically commented on the manuscript.

\section{Editorial note}

This paper has been accepted based in part on peerreview conducted by another journal and the authors' response and revisions as well as expedited peer-review in Oncotarget.

\section{REFERENCES}

1. El-Serag HB. Hepatocellular carcinoma. N Engl J Med. 2011; 365: 1118-27. doi: 10.1056/NEJMra1001683.

2. Marquardt JU, Andersen JB, Thorgeirsson SS. Functional and genetic deconstruction of the cellular origin in liver cancer. Nat Rev Cancer. 2015; 15: 653-67. doi: 10.1038/ $\operatorname{nrc} 4017$.

3. Karin M. Nuclear factor-kappaB in cancer development and progression. Nature. 2006; 441: 431-6.

4. Llovet JM, Ricci S, Mazzaferro V, Hilgard P, Gane E, Blanc JF, de Oliveira AC, Santoro A, Raoul JL, Forner A, Schwartz M, Porta C, Zeuzem S, et al. Sorafenib in advanced hepatocellular carcinoma. N Engl J Med. 2008; 359: 378-90. doi: 10.1056/NEJMoa0708857.

5. Luedde T, Schwabe RF. NF-kappaB in the liver--linking injury, fibrosis and hepatocellular carcinoma. Nat Rev Gastroenterol Hepatol. 2011; 8: 108-18. doi: 10.1038/ nrgastro.2010.213.

6. Hernandez-Gea V, Toffanin S, Friedman SL, Llovet JM.
Role of the microenvironment in the pathogenesis and treatment of hepatocellular carcinoma. Gastroenterology. 2013; 144: 512-27. doi: 10.1053/j.gastro.2013.01.002.

7. He G, Dhar D, Nakagawa H, Font-Burgada J, Ogata H, Jiang Y, Shalapour S, Seki E, Yost SE, Jepsen K, Frazer KA, Harismendy O, Hatziapostolou M, et al. Identification of liver cancer progenitors whose malignant progression depends on autocrine IL-6 signaling. Cell. 2013; 155: 38496. doi: 10.1016/j.cell.2013.09.031.

8. Marquardt JU, Seo D, Andersen JB, Gillen MC, Kim MS, Conner EA, Galle PR, Factor VM, Park YN, Thorgeirsson SS. Sequential transcriptome analysis of human liver cancer indicates late stage acquisition of malignant traits. J Hepatol. 2014; 60: 346-53. doi: 10.1016/j.jhep.2013.10.014.

9. Budhu A, Forgues M, Ye QH, Jia HL, He P, Zanetti KA, Kammula US, Chen Y, Qin LX, Tang ZY, Wang XW. Prediction of venous metastases, recurrence, and prognosis in hepatocellular carcinoma based on a unique immune response signature of the liver microenvironment. Cancer Cell. 2006; 10: 99-111. doi: 10.1016/j.ccr.2006.06.016.

10. Hoshida Y, Villanueva A, Kobayashi M, Peix J, Chiang DY, Camargo A, Gupta S, Moore J, Wrobel MJ, Lerner J, Reich M, Chan JA, Glickman JN, et al. Gene expression in fixed tissues and outcome in hepatocellular carcinoma. N Engl J Med. 2008; 359: 1995-2004.

11. Feng GS. Conflicting roles of molecules in hepatocarcinogenesis: paradigm or paradox. Cancer Cell. 2012; 21: 150-4. doi: 10.1016/j.ccr.2012.01.001.

12. Li SC, Tachiki LM, Kabeer MH, Dethlefs BA, Anthony MJ, Loudon WG. Cancer genomic research at the crossroads: realizing the changing genetic landscape as intratumoral spatial and temporal heterogeneity becomes a confounding factor. Cancer Cell Int. 2014; 14: 115. doi: 10.1186/s12935014-0115-7.

13. Zhang DY, Goossens N, Guo J, Tsai MC, Chou HI, Altunkaynak C, Sangiovanni A, Iavarone M, Colombo M, Kobayashi M, Kumada H, Villanueva A, Llovet JM, et al. A hepatic stellate cell gene expression signature associated with outcomes in hepatitis C cirrhosis and hepatocellular carcinoma after curative resection. Gut. 2015. doi: 10.1136/ gutjnl-2015-309655.

14. Greten TF, Wang XW, Korangy F. Current concepts of immune based treatments for patients with HCC: from basic science to novel treatment approaches. Gut. 2015; 64: 8428. doi: 10.1136/gutjnl-2014-307990.

15. Roessler S, Long EL, Budhu A, Chen Y, Zhao X, Ji J, Walker R, Jia HL, Ye QH, Qin LX, Tang ZY, He P, Hunter $\mathrm{KW}$, et al. Integrative genomic identification of genes on $8 \mathrm{p}$ associated with hepatocellular carcinoma progression and patient survival. Gastroenterology. 2012; 142: 957-66 e12. doi: 10.1053/j.gastro.2011.12.039.

16. Rosty C, Sheffer M, Tsafrir D, Stransky N, Tsafrir I, Peter M, de Cremoux P, de La Rochefordiere A, Salmon R, Dorval T, Thiery JP, Couturier J, Radvanyi F, et al. Identification of a proliferation gene cluster associated 
with HPV E6/E7 expression level and viral DNA load in invasive cervical carcinoma. Oncogene. 2005; 24: 7094104. doi: 10.1038/sj.onc. 1208854 .

17. Ben-Porath I, Thomson MW, Carey VJ, Ge R, Bell GW, Regev A, Weinberg RA. An embryonic stem cell-like gene expression signature in poorly differentiated aggressive human tumors. Nat Genet. 2008; 40: 499-507. doi: 10.1038/ ng. 127.

18. Govaere O, Wouters J, Petz M, Vandewynckel YP, Van den Eynde K, Van den Broeck A, Verhulst S, Dolle L, Gremeaux L, Ceulemans A, Nevens F, van Grunsven LA, Topal B, et al. Laminin-332 sustains chemoresistance and quiescence as part of the human hepatic cancer stem cell niche. J Hepatol. 2016; 64: 609-17. doi: 10.1016/j. jhep.2015.11.011.

19. Andersen JB, Factor VM, Marquardt JU, Raggi C, Lee YH, Seo D, Conner EA, Thorgeirsson SS. An integrated genomic and epigenomic approach predicts therapeutic response to zebularine in human liver cancer. Sci Transl Med. 2010; 2: 54ra77. doi: 10.1126/scitranslmed.3001338.

20. Elsharkawy AM, Mann DA. Nuclear factor-kappaB and the hepatic inflammation-fibrosis-cancer axis. Hepatology. 2007; 46: 590-7. doi: 10.1002/hep.21802.

21. He G, Karin M. NF-kappaB and STAT3 - key players in liver inflammation and cancer. Cell Res. 2011; 21: 159-68. doi: 10.1038/cr.2010.183.

22. Seton-Rogers S. Field effect. Nat Rev Cancer. 2012; 12: 508-9. doi: 10.1038/nrc3324.

23. Hanahan D, Weinberg RA. Hallmarks of cancer: the next generation. Cell. 2011; 144: 646-74. doi: 10.1016/j. cell.2011.02.013.

24. Wang K, Lim HY, Shi S, Lee J, Deng S, Xie T, Zhu Z, Wang Y, Pocalyko D, Yang WJ, Rejto PA, Mao M, Park CK, et al. Genomic landscape of copy number aberrations enables the identification of oncogenic drivers in hepatocellular carcinoma. Hepatology. 2013; 58: 706-17. doi: 10.1002/hep.26402.

25. Guichard C, Amaddeo G, Imbeaud S, Ladeiro Y, Pelletier L, Maad IB, Calderaro J, Bioulac-Sage P, Letexier M, Degos F, Clement B, Balabaud C, Chevet E, et al. Integrated analysis of somatic mutations and focal copynumber changes identifies key genes and pathways in hepatocellular carcinoma. Nat Genet. 2012; 44: 694-8. doi: 10.1038/ng.2256.

26. Ma S, Chan KW, Hu L, Lee TK, Wo JY, Ng IO, Zheng BJ, Guan XY. Identification and characterization of tumorigenic liver cancer stem/progenitor cells. Gastroenterology. 2007; 132: 2542-56.

27. Yamashita T, Ji J, Budhu A, Forgues M, Yang W, Wang HY, Jia H, Ye Q, Qin LX, Wauthier E, Reid LM, Minato H, Honda M, et al. EpCAM-positive hepatocellular carcinoma cells are tumor-initiating cells with stem/progenitor cell features. Gastroenterology. 2009; 136: 1012-24. doi: 10.1053/j.gastro.2008.12.004.
28. Libbrecht L, Desmet V, Van DB, Roskams T. The immunohistochemical phenotype of dysplastic foci in human liver: correlation with putative progenitor cells. JHepatol. 2000; 33: 76-84.

29. Roskams T, Desmet V. Ductular reaction and its diagnostic significance. SeminDiagnPathol. 1998; 15: 259-69.

30. Zhao W, Wang L, Han H, Jin K, Lin N, Guo T, Chen Y, Cheng H, Lu F, Fang W, Wang Y, Xing B, Zhang Z. 1B501 , a $\mathrm{mAb}$ raised against recurrent tumor cells, targets liver tumor-initiating cells by binding to the calcium channel alpha2delta1 subunit. Cancer Cell. 2013; 23: 541-56. doi: 10.1016/j.ccr.2013.02.025.

31. Li L, Neaves WB. Normal stem cells and cancer stem cells: the niche matters. Cancer Res. 2006; 66: 4553-7.

32. Plaks V, Kong N, Werb Z. The cancer stem cell niche: how essential is the niche in regulating stemness of tumor cells? Cell Stem Cell. 2015; 16: 225-38. doi: 10.1016/j. stem.2015.02.015.

33. Feinberg AP, Ohlsson R, Henikoff S. The epigenetic progenitor origin of human cancer. NatRevGenet. 2006; 7: 21-33.

34. Shin S, Wangensteen KJ, Teta-Bissett M, Wang YJ, Mosleh-Shirazi E, Buza EL, Greenbaum LE, Kaestner KH. Genetic Lineage Tracing Analysis of the Cell of Origin of Hepatotoxin-Induced Liver Tumors in Mice. Hepatology. 2016. doi: 10.1002/hep.28602.

35. Marquardt JU. Deconvolution of the cellular origin in hepatocellular carcinoma - hepatocytes take the center stage. Hepatology. 2016. doi: 10.1002/hep.28671.

36. Clarke MF, Dick JE, Dirks PB, Eaves CJ, Jamieson CH, Jones DL, Visvader J, Weissman IL, Wahl GM. Cancer stem cells--perspectives on current status and future directions: AACR Workshop on cancer stem cells. Cancer Res. 2006; 66: 9339-44.

37. Li F, Tiede B, Massague J, Kang Y. Beyond tumorigenesis: cancer stem cells in metastasis. Cell Res. 2007; 17: 3-14.

38. Sprinzl MF, Puschnik A, Schlitter AM, Schad A, Ackermann K, Esposito I, Lang H, Galle PR, Weinmann A, Heikenwalder M, Protzer U. Sorafenib inhibits macrophageinduced growth of hepatoma cells by interference with insulin-like growth factor-1 secretion. J Hepatol. 2015; 62: 863-70. doi: 10.1016/j.jhep.2014.11.011.

39. Brunner SM, Rubner C, Kesselring R, Martin $M$, Griesshammer E, Ruemmele P, Stempfl T, Teufel A, Schlitt HJ, Fichtner-Feigl S. Tumor-infiltrating, interleukin-33producing effector-memory $\mathrm{CD} 8(+) \mathrm{T}$ cells in resected hepatocellular carcinoma prolong patient survival. Hepatology. 2015; 61: 1957-67. doi: 10.1002/hep.27728.

40. Quigley M, Pereyra F, Nilsson B, Porichis F, Fonseca C, Eichbaum Q, Julg B, Jesneck JL, Brosnahan K, Imam S, Russell K, Toth I, Piechocka-Trocha A, et al. Transcriptional analysis of HIV-specific CD8 $+\mathrm{T}$ cells shows that PD-1 inhibits T cell function by upregulating BATF. Nat Med. 2010; 16: 1147-51. doi: 10.1038/nm.2232. 
41. Cariani E, Pilli M, Zerbini A, Rota C, Olivani A, Pelosi G, Schianchi C, Soliani P, Campanini N, Silini EM, Trenti T, Ferrari C, Missale G. Immunological and molecular correlates of disease recurrence after liver resection for hepatocellular carcinoma. PLoS One. 2012; 7: e32493. doi: 10.1371/journal.pone.0032493.

42. Calderaro J, Rousseau B, Amaddeo G, Mercey M, Charpy C, Costentin C, Luciani A, Zafrani ES, Laurent A, Azoulay D, Lafdil F, Pawlotsky JM. Programmed death ligand 1 expression in hepatocellular carcinoma: Relationship With clinical and pathological features. Hepatology. 2016. doi: 10.1002/hep.28710.
43. Sangro B, Gomez-Martin C, de la Mata M, Inarrairaegui M, Garralda E, Barrera P, Riezu-Boj JI, Larrea E, Alfaro C, Sarobe P, Lasarte JJ, Perez-Gracia JL, Melero I, et al. A clinical trial of CTLA-4 blockade with tremelimumab in patients with hepatocellular carcinoma and chronic hepatitis C. J Hepatol. 2013; 59: 81-8. doi: 10.1016/j. jhep.2013.02.022.

44. Marquardt JU, Raggi C, Andersen JB, Seo D, Avital I, Geller D, Lee YH, Kitade M, Holczbauer A, Gillen MC, Conner EA, Factor VM, Thorgeirsson SS. Human hepatic cancer stem cells are characterized by common stemness traits and diverse oncogenic pathways. Hepatology. 2011; 54: 1031-42. doi: 10.1002/hep.24454. 